\title{
Thunderstorm-asthma, two cases observed in Northern Italy
}

\author{
Maria Francesca Spina, ${ }^{1}$ Paolo Innocente Banfi, ${ }^{1}$ Antonello Nicolini ${ }^{2}$ \\ ${ }^{I}$ IRCCS Fondazione Don Carlo Gnocchi, Milan \\ ${ }^{2}$ Respiratory Diseases Unit, General Hospital of Sestri Levante (GE), Italy
}

\begin{abstract}
Thunderstorm asthma is a rare event: in this letter we describe two cases observed during the same month of 2018 at an Italian Emergency department, assessed by the same medical team and according to the same methodology and approach. Given the infrequency of such a phenomenon and the debate around its nature, frequency, and - at times existence, we strongly believe it is important for all specialists who observe such cases to report them, building an evidence base to expand its knowledge and understanding.
\end{abstract}

Key words: Asthma; thunderstorm asthma; respiratory allergens.

Correspondence: Maria Francesca Spina, Fondazione don Gnocchi - IRCCS S.Maria Nascente, Via A. Capecelatro 66, 20148 Milan, Italy. E-mail: mspina@dongnocchi.it

Contributions: All the authors made a substantive intellectual contribution. All the authors have read and approved the final version of the manuscript and agreed to be accountable for all aspects of the work.

Conflict of interest: The authors declare no conflict of interest.

Funding: None.

Availability of data and materials: Research data are stored in the hospital database.

Ethics approval and consent to participate: Not applicable.

Case presentation: This information was never presented in any abstract or congress. 
To the Editor

Thunderstorm asthma is defined as the occurrence of asthma epidemics during or after thunderstorm in the pollen season [1]. During thunderstorm pollen grains are concentrated at ground level; moreover, the greater humidity breaks pollen grains in smaller particles that easily reach the lower respiratory tract. This hypothesis can explain the higher number of cases of severe and fatal asthma during thunderstorm. Urban air pollution may be a negative associated co-factor.

The main epidemics were reported from Australia in 2010 and 2016, from London in 1994, from Naples in 2004 [2-4], and from Kuwait in 2020 (about data on events occurred in 2016) [5].

While servicing at the emergency department (ED) of the Ospedale Fatebenefratelli and Oftalmico in Milan in May 2018, we visited two patients with severe asthma. The patients were females (45 and 41 years old), with a history of allergic rhinitis and mild asthma and skin test positivity to grass pollen. In the weeks when the attacks occurred, pollen count in the air was high, and thunderstorms occurred on the nights of $8^{\text {th }}$ and $16^{\text {th }}$ May 2018: both patients were outdoor when the storm broke out. The first one was smoking a cigarette after dinner, the second one was in her home terrace before having dinner. In both patients, symptoms including dyspnea, cough and dysphonia started within 30 min after outdoor exposure, despite they were under treatment with inhaled corticosteroid. Clinical data are summarized in Table 1.

Thorax X-ray was normal as well as blood examinations (white cells blood count, C-reactive protein, liver and kidney function).

Both patients were diagnosed with severe asthma attack and they were thus promptly treated accordingly. We administered them intravenous (iv) corticosteroids, inhaled corticosteroids, beta2 -agonists and muscarinic antagonists, magnesium sulfate 2 gr iv. once in $30 \mathrm{~min}$ and oxygen. Also, iv proton pump inhibitors were administered.

Table 1. Patients clinical data.

\begin{tabular}{lcc} 
& Patient 1 & Patient 2 \\
Age (yrs) & 45 & 41 \\
Sex & F & F \\
\hline History of allergic rhinitis & Yes & Yes \\
History of allergic asthma & Yes, mild & Yes, mild \\
\hline Therapy at the evaluation & Low dose inhaled & Low dose inhaled \\
& steroids & steroid \\
Cigarette smoke & Yes & No \\
\hline Respiratory frequency at hospitalization & $40 /$ min & $35 /$ min \\
Oxygen saturation & $96 \%$ & $96 \%$ \\
\hline Other therapies & No & No \\
Other asthma co-morbidities & No & Gastric reflux \\
\hline
\end{tabular}

Clinical improvement was observed within $1 \mathrm{~h}$ of treatment in the ED. We followed both patients all night long, without any need of intensive care support, interrupting clinical observation after 12 $\mathrm{h}$ post-event. Therapy with both inhaled corticosteroids and bronchodilators was prescribed at discharge, and follow up assessment evaluation by an allergist and pulmonologist was scheduled, conducted at our present institution.

At present, when searching PubMed for the keyword "thunderstorm asthma", 127 papers are returned; the Australian experiences in 2010 and 2016 remain the most cited ones. Further observations in other countries such as England, Italy, and Kuwait are available. In the paper from Italy, a retrospective evaluation of the ED accesses from 2013 to 2015 in the Veneto region questioned the consistency of thunderstorm asthma, since it did not find an increase of cases of severe asthma during thunderstorms [6]. On the contrary, our experience supports the rest of the literature, suggesting that thunderstorm asthma must be considered as a specific clinical entity, which warrants a correct patient education to avoid cases of fatal asthma. Also, since patients with these severe asthma attacks would refer to EDs, where it is possible that an asthma specialist would not be available, they might be assessed and treated appropriately but without connecting their onset to the thunderstorm. Consequently, we think it to be an important effort for the whole scientific community to report any time it is possible all relatively rare cases they observe, in an effort to increase awareness within the clinical community, motivating ED physicians to ask targeted questions and always refer such patients to the appropriate specialists for further assessment and education.

\section{References}

1. D'Amato G, Vitale C, D'Amato M, Cecchi L, Liccardi G, Molino A, et al. Thunderstorm-related asthma: what happens and why. Clin Exp Allergy 2016;46:390-6.

2. Schumacher MJ. Thunderstorm asthma. Intern Med J 2017;47:605-7.

3. D'Amato M, Cecchi L, Annesi-Maesano I, D'Amato G. News on climate change, air pollution, and allergic triggers of asthma. J Investig Allergol Clin Immunol 2018;28:91-7.

4. D'Amato G, Annesi-Maesano I, Cecchi L, D'Amato M. Latest news on relationship between thunderstorms and respiratory allergy, severe asthma, and deaths for asthma. Allergy 2019;74:9-11.

5. Ali F, Behbehani N, Alomair N, Taher A. Fatal and near-fatal thunderstorm asthma epidemic in a desert country. Ann Thorac Med 2019;14:155-60.

6. Caminati M, Senna G, Vianello A, Ricci G, Bellamoli R, Longhi S, et al. Thunderstorm asthma: a critical appraisal based on clinical practice. J Investig Allergol Clin Immunol 2018;28:273-5.

Received for publication: 25 May 2020. Accepted for publication: 23 July 2020.

This work is licensed under a Creative Commons Attribution-NonCommercial 4.0 International License (CC BY-NC 4.0).

(C) Copyright: the Author(s), 2020

Licensee PAGEPress, Italy

Multidisciplinary Respiratory Medicine 2020; 15:679

doi:10.4081/mrm.2020.679 